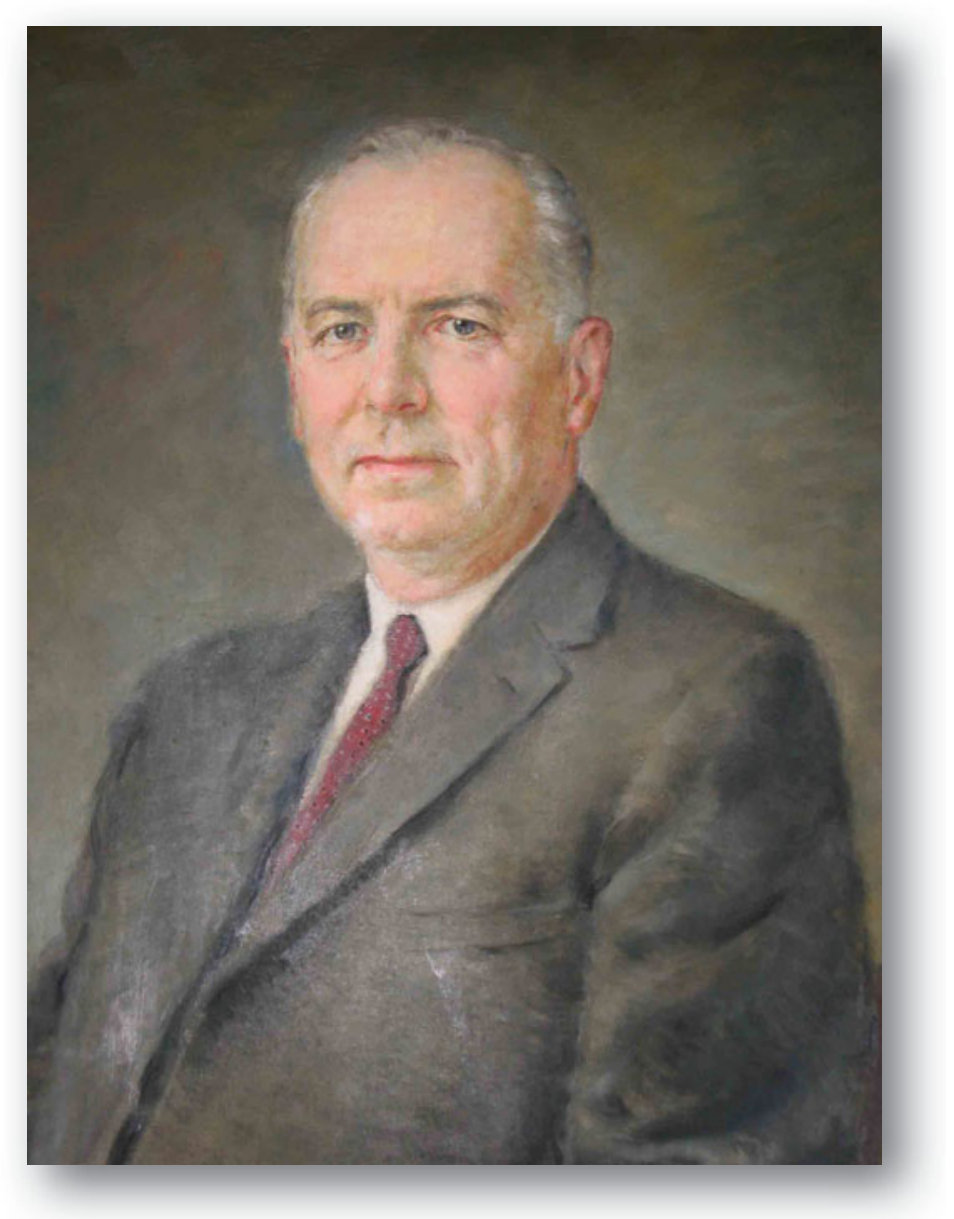

KENNETH W. SPENCE

(Cloy Kent, 1961)

Courtesy of the Department of Psychology, University of Iowa

\title{
A Tribute to K. W. Spence (1907-1967)
}

Several years ago, it occurred to me that we were nearing K. W. Spence's 100th birthday. What better way to celebrate his birth than to bring leading researchers and theorists to the University of Iowa to gain a better understanding of Spence's work and legacy?

So, I initiated planning for the event, I enlisted the help of John Freeman in my department and Allan Wagner at Yale University to organize the event, and I obtained financial support for the event from the University of Iowa, its College of Liberal Arts and Sciences, and its Department of Psychology, in order to make this possibility a reality.

The SpenceFest, as it was termed, was held on September 21 and 22 of 2007. During the 2 days of the event, we heard a series of extremely engaging talks by outstanding researchers and theorists in the areas of learning and motivation. Many different approaches were highlighted, including behavioral, physiological, and computational.

The papers in this special issue of Learning \& Behavior share the expanded contents of those talks with the general community of psychological scientists. The reader will see that Spence's legacy is very much a continuing one. We are all the better for the contributions of this eminent man. 